УДК 811

DOI: 10.35750/2071-8284-2019-4-99-106

Ю.А. Грачев

кандидат педагогических наук, доцент

Санкт-Петербургский университет МВД России

Российская Федерация, 188510, Санкт-Петербург, ул. Аврова, д. 33

ORCID : 0000-0002-0168-1624. E-mail: mail@univermvd.ru

А.В. Никишкин

кандидат юридических наук

Санкт-Петербургский университет МВД России

Российская Федерация, 188510, Санкт-Петербург, ул. Аврова, д. 33

ORCID : 0000-0001-8306-9764.E-mail: niksa78@yandex.ru

\title{
Е.В. Ветрова
}

Санкт-Петербургский университет МВД России

Российская Федерация, 188510, Санкт-Петербург, ул. Аврова, д. 33

ORCID : 0000-0002-0428-1650. E-mail: vev2106@yandex.ru

\section{Меры по противодействию коррупции в Российской Федерации на современном этапе развития}

\begin{abstract}
Аннотация: Данная научная статья подготовлена на основе нормативных правовых актов, материалов следственной и судебной практики. В ней рассматриваются наиболее актуальные вопросы противодействия коррупции в современной России.

Особое место уделено изложению имеющихся проблем по предупреждению, пресечению и раскрытию преступлений коррупционной направленности на современном этапе развития Российской Федерации. Научный и практический интерес представляют изложенные меры, направленные на эффективное противодействие коррупционным проявлениям, а также предложения по их совершенствованию с учётом сложившейся практики и положительного опыта зарубежных стран.

В статье рассматриваются актуальные вопросы пропаганды антикоррупционного поведения и антикоррупционного правосознания на юридических факультетах и с личным составом правоохранительных органов, в частности совершенствования критериев работы по отбору кандидатов на должности сотрудников. Обосновывается целесообразность и применимость изложенных мер не только к действующим и будущим сотрудникам правоохранительных органов, но и ко всем государственным служащим и работникам иных отраслей, подверженных коррупционным рискам и конфликту интересов.

Подводятся итоги применения антикоррупционных мер при правильном их использовании, а также соблюдение принципов непрерывности и повсеместности их проведения. Указывается на то, что применение вышеуказанных средств, мер и принципов антикоррупционного поведения государственных служащих приводит к значительному уменьшению количества коррупционных преступлений в органах внутренних дел и затрудняет в дальнейшем появление преступных посягательств коррупционной направленности.

Ключевые слова: коррупционные проявления, самосознание граждан, нормативные правовые акты, антикоррупционное законодательство, противодействие коррупции, получение взятки.
\end{abstract}

Для цитирования: Грачев Ю.А., Никишкин А.В., Ветрова Е.В. Меры по противодействию коррупции в Российской Федерации на современном этапе развития // Вестник Санкт-Петербургского университета МВД России. - 2019. - № 4 (84). - С. 99-106. DOI: 10.35750/2071-8284-2019-4-99-106.

Yuri A. Grachev

Cand. Sci. (Ped.), Docent

Saint-Petersburg University of the MIA of Russia

33, Avrova str., Saint-Petersburg, 188510, Russian Federation

ORCID : 0000-0002-0168-1624.E-mail:mail@univermvd.ru

\section{Alexander V. Nikishkin}

Cand. Sci. (Jurid.)

Saint-Petersburg University of the MIA of Russia

33, Avrova str., Saint-Petersburg, 188510, Russian Federation

ORCID : 0000-0001-8306-9764.E-mail: niksa78@yandex.ru 
Elena V. Vetrova

Saint-Petersburg University of the MIA of Russia

33, Avrova str., Saint-Petersburg, 188510, Russian Federation

ORCID : 0000-0002-0428-1650.E-mail:vev2106@yandex.ru

\title{
Anti-corruption measures in the Russian Federation at the present stage of development
}

\begin{abstract}
Annotation: This scientific article is prepared on the basis of normative legal acts, materials of investigative and judicial practice, it deals with the most pressing issues of combating corruption in modern Russia.

A special place is given to the presentation of the existing problems of prevention, suppression and disclosure of crimes of corruption at the present stage of development of the Russian Federation.

Scientific and practical interest is represented by the stated measures directed on effective counteraction to corruption manifestations, and also offers on their improvement taking into account the developed practice and positive experience of foreign countries.

The article discusses and reveals the topical issues of promotion of anti-corruption behavior and anticorruption legal awareness in law schools and with the personnel of law enforcement agencies, in particular, improving the criteria for the selection of candidates for positions of employees.

The expediency and applicability of the above measures not only to current and future law enforcement officers, but also to all civil servants and employees of other industries exposed to corruption risks and conflicts of interest are fully justified.

The results of the application of anti-corruption measures with their proper use, as well as compliance with the principles of continuity and ubiquity of their implementation. It is indicated that the use of the above means, measures and principles of anti-corruption behavior of civil servants leads to a significant reduction in the number of corruption crimes in the internal Affairs bodies and complicates the further appearance of this type of criminal attacks of corruption orientation.

Keywords: Corruption manifestations, self-awareness of citizens, normative legal acts, anti-corruption legislation, anti-corruption, bribery.

For citation: Grachev Y.A., Nikishkin A.V., Vetrova E.V. Anti-corruption measures in the Russian Federation at the present stage of development // Vestnik of St. Petersburg University of the Ministry of Internal Affairs of Russia. - 2019. - № 4 (84). - P. 99-106. DOI: 10.35750/2071-8284-2019-4-99-106.
\end{abstract}

При организации мер по противодействию коррупционным проявлениям следует воздействовать на самосознание граждан, совершенствовать нравственно-правовое воспитание с раннего возраста и прилагать усилия к развитию нетерпимого отношения к преступлениям коррупционной направленности, проводить политику жёстких мер за совершение коррупционных преступлений.

Первоочередным в решении вопроса о противодействии коррупции, предупреждении, пресечении и раскрытии преступлений данного вида на современном этапе выступает внесение изменений в действующее законодательство об обязанностях физических и юридических лиц ежегодно предоставлять сведения о своих доходах, расходах, об имуществе и обязательствах имущественного характера своих супругов и несовершеннолетних детей, а также об ответственности за непредоставление или несвоевременное предоставление этих сведений [1, с. 121].

Данное изменение в законодательстве Российской Федерации дало возможность уменьшить число коррупционных преступлений, совершаемых лицами, использующими своё служебное положение, и значительно осложнить их реализацию. Данное изменение включает в сферу своего влияния высших должностных лиц государства, сенаторов Совета Федерации и депутатов Государственной Думы Российской Федерации, которые ранее имели иммунитет от правосудия.

Необходимо подчеркнуть, что нормативные правовые акты (Федеральный закон Российской Федерации от 25 декабря 2008 года № 273-Ф3 «О противодействии коррупции», Указание Генпрокуратуры Российской Федерации № 797/11 и МВД России № 2 от 13 декабря 2016 года «О введении в действие перечней статей Уголовного Кодекса Российской Федерации, используемых при формировании статистической отчётности», Федеральный закон Российской Федерации от 17 июля 2009 года № 172-Ф3 «Об антикоррупционной экспертизе нормативных правовых актов и проектов нормативных правовых актов», Указание Генпрокуратуры Российской Федерации № 487/11 и МВД России № 1 от 12 июля 2019 года «О введении в действие 
перечней статей Уголовного Кодекса Российской Федерации, используемых при формировании статистической отчётности»), ориентированные на противодействие коррупционным проявлениям, сосредоточиваются в первую очередь на их предупреждении, пресечении и раскрытии, однако никоим образом не затрагивают предпосылки и причины преступлений данного вида. Вышеуказанные нормативные правовые акты в большинстве случаев не уделяют достаточного внимания решению поставленной перед государством основной цели - формированию в гражданском обществе антикоррупционного поведения и антикоррупционного правосознания у его членов.

Государственные меры по противодействию коррупционным преступлениям на современном этапе заключаются в большинстве своём только в бесчисленном количестве заседаний государственных органов, учреждений и комитетов, а также в интервью с представителями вышеперечисленных организаций. В качестве примера можно привести слова заместителя председателя Комитета Совета Федерации по конституционному законодательству и государственному строительству К.Э. Добрынина, отметившего необходимость координации общества и власти для противодействия коррупции: «Коррупционные преступления являются особо скрытыми, поэтому данная проблема обязательно должна освещаться средствами массовой информации и доводиться до широких масс населения, и именно это будет являться движущей силой, обеспечивающей процесс просветительства общественности в сфере коррупционных проявлений и раскрытия коррупционных преступлений и посягательств. Также помощь в рассматриваемом вопросе должны оказывать общественные организации, осуществляющие взаимодействие с органами правопорядка и государственной власти» $[2$, с. 19].

Инициативы в области антикоррупционного законодательства, а также решения, принимаемые в данном направлении, следует дополнить заслушиваниями должностных лиц и обсуждениями неравнодушных граждан, активно участвующих в жизни общества и государства. Данные обсуждения организуются в виде конференций, дискуссий, диспутов и круглых столов, ведущая роль в которых отводится государственной власти и гражданскому обществу. Меры воздействия, направленные на выработку конкретных решений в антикоррупционном законодательстве, являются основным фактором, стимулирующим выработку решений по контролю и пресечению коррупционных проявлений, и дают возможность реально оценить правильность выбора методов и направления работы по противодействию коррупции в стране. Общество готово дать объективную оценку происходящим событиям и активно сотрудничать с правоохранительными органами, поскольку население видит конструктивные сдвиги в направлении взаимодействия общества и государства [3, с. 84].

Наиболее значимым фактором, влияющим на пресечение коррупционных проявлений, выступает специально организованный мониторинг деятельности органов государственной власти разных уровней, который выявляет средний показатель коррупции в стране, проводит сравнительный анализ, сопоставляя полученные данные с аналогичными показателями предшествующих периодов, а также способствует тому, что информация становится доступной для широких масс. Так, по данным ГИАЦ МВД России, в последние годы удельный вес зарегистрированных преступлений коррупционной направленности не превышает $2 \%$ от общего количества зарегистрированных преступлений по России. В 2012 году - 36470 преступлений, в 2013 г. - 42506, в 2014 г. - 32204 преступления, в 2015 г. - 32455, в 2016 г. - 32924 преступления, в 2017 году - 29634 преступления, в 2018 г. - 30495 преступлений. Таким образом, уровень зарегистрированных преступлений указанного вида за последние годы не имел резкой тенденции к изменению. Это в первую очередь объясняется планомерной повсеместной и стабильной профилактической деятельностью и проводимой в стране позитивной антикоррупционной политикой.

Достичь положительного эффекта можно, установив публично-правовой статус должностных лиц Российского государства и подробно регламентировав их служебную деятельность. Для достижения такого эффекта важно направить усилия на контроль за процессом замещения должностей государственной и муниципальной службы, чтобы избежать возможных случаев протекционизма $[4$, с. 56].

Учёные, рассматривающие проблему коррупционной преступности в России, В.А. Егоров и Н.А. Яковлев, в своей статье «Современный взгляд на коррупцию и методы борьбы с её проявлением» отмечают: «Сегодня остро встаёт вопрос о необходимости ужесточения мер уголовной ответственности за "незаконное обогащение” лиц, обладающих распределительными полномочиями, в исключительных случаях, на- 
пример, как это сделано в Китае, посредством смертной казни коррупционера. В Китае за взятку или растрату государственных средств в сумме 3 млн юаней, что равноценно 30 млн рублей, чиновнику может быть назначена смертная казнь. Эта мера наказания может стать сдерживающим фактором» [1, с. 119].

В рамках осуществления целенаправленных мер по организации противодействия коррупционным проявлениям 29 июня 2018 года Президент Российской Федерации в целях противодействия коррупции в Российской Федерации утвердил Национальный план противодействия коррупции на 2018 - 2020 гг. (Указ Президента Российской Федерации № 378). В документе ставится акцент на меры, предпринимаемые в отношении коррупционеров с чрезмерным административным влиянием. Данное явление существенно затрудняет работу большинства общественных институтов власти, ограничивает возможность проведения изменений в социальной сфере и препятствует развитию национальных экономических реформ, вызывает особую озабоченность в современном гражданском обществе и скептицизм в отношении органов государственной власти. В результате создаётся негативный имидж России на международной арене. Коррупция правомерно рассматривается как одна из угроз безопасности Российской Федерации. 17 июля 2009 года был издан Федеральный закон Российской Федерации № 172-Ф3 (в ред. от 11 октября 2018 года) «Об антикоррупционной экспертизе нормативных правовых актов и проектов нормативных правовых актов».

Были приняты:

- Федеральный закон Российской Федерации от 3 декабря 2012 г. № 230-Ф3 «О контроле за соответствием расходов лиц, замещающих государственные должности, и иных лиц их доходам»;

- Федеральный закон Российской Федерации от 7 мая 2013 г. № 79-Ф3 «О запрете отдельным категориям лиц открывать и иметь счета (вклады), хранить наличные денежные средства и ценности в иностранных банках, расположенных за пределами территории Российской Федерации, владеть и (или) пользоваться иностранными финансовыми инструментами»;

- Федеральный закон Российской Федерации от 7 мая 2013 г. № 102-Ф3 «О внесении изменений в отдельные законодательные акты Российской Федерации в связи с принятием Федерального закона "О запрете отдельным категориям лиц открывать и иметь счета (вклады), хранить наличные денежные средства и ценности в иностранных банках, расположенных за пределами территории Российской Федерации, владеть и (или) пользоваться иностранными финансовыми инструментами"».

В связи с этим разработка мер по противодействию коррупции, прежде всего в целях устранения её значимых недостатков, и организация необходимых мероприятий, направленных на обеспечение мер по развитию гражданского общества в частности и государства в целом, становится первостепенной задачей по повышению результативности деятельности, выявления и пресечения коррупционных проявлений. К сожалению, очень немногие уголовные дела этой категории доходят до суда. Для плодотворного противодействия таким преступлениям важно активизировать профилактические мероприятия по пресечению и предотвращению коррупционных посягательств во всех сферах общества и государства.

Гражданское общество и государство стремятся разработать мероприятия по организации механизма, который даст возможность организовать разработку основных методов и принципов, при которых государственный аппарат будет вовлечён в процесс противодействия преступлениям коррупционной направленности.

Исходя из вышесказанного, авторы статьи предлагают ряд мер, необходимых для эффективного противодействия проявлениям коррупции в Российской Федерации.

1. Реформирование в сфере законодательных актов.

«Нет сомнения, что в последние годы разработаны основные направления государственной политики Российской Федерации в области противодействия коррупции». Данные направления деятельности по недопущению коррупционной преступности предусмотрены дисциплинарной, административной, гражданско-правовой и уголовной ответственностью должностных лиц и граждан» [6, с. 114].

Несмотря на принимаемые меры по противодействию коррупционным проявлениям, сохраняется множество неразрешённых вопросов, которые позволяют лицам, осуществляющим преступную деятельность, оставаться безнаказанными или частично уходить от ответственности, предусмотренной действующим законодательством.

Примером может служить содержание статьи 290 Уголовного Кодекса Российской Федерации, в которой предусмотрено наказание в виде лишения свободы и штрафа в размере от 3 до 
5 млн рублей и запрет на замещение определённых должностей или занятие определёнными видами деятельности до 15 лет, для лиц, занимающих государственные должности и получивших взятку в особо крупном размере путём вымогательства за противозаконные действия, что само по себе подразумевает возможность избежать такой суровой меры наказания, как реальное лишение свободы.

Несомненно, назначение наказания в полной мере определяется конкретными обстоятельствами дела, но вопреки этому, за дачу и получение взятки в размере более одного миллиона рублей, по нашему мнению, мера пресечения в виде заключения под стражу должна назначаться во всех случаях без исключения. Сомнительной выступает также мера наказания, лишающая права лицо, осуждённое за коррупционное преступление, занимать определённые должности или заниматься определённой деятельностью на какой-либо срок.

Действительно, после отбытия наказания уличённый в получении взятки сотрудник органов правопорядка может вернуться на свою должность, что вызывает справедливые нарекания. Никто не может дать гарантий, что гражданин, единожды нарушивший закон, не повторит данное деяние вновь. В связи с вышеизложенным считаем, что в органах правопорядка необходимо исключить риск рецидива со стороны запятнавших себя сотрудников: ведь ранее привлечённые к ответственности взяточники будут опираться на накопленный опыт и примут во внимание допущенные ошибки, и привлечь их повторно к ответственности за аналогичные преступления будет гораздо сложнее.

Вносить значимые изменения в действующие законодательные акты страны необходимо, опираясь не только на неотвратимость наказания, но и на его адекватность. Если за дачу и получение взятки в крупном и особо крупном размере законодатель считает нужным найти альтернативу реальному тюремному сроку, заменив его на уголовный штраф, необходимо предусмотреть введение пожизненного лишения права заниматься определёнными видами деятельности и занимать конкретные государственные должности, а одновременно с этим рассмотреть возможность введения дополнительного вида наказания - конфискации имущества, принадлежащего осуждённому лицу и членам его семьи, а также невозможность получения данными лицами пенсионного обеспечения. Вышеуказанные меры, применяемые в полном объёме, смогут значительно сократить число преступлений коррупционной направленности.

Рассматриваемые нами меры направлены в первую очередь на компенсацию причинённого ущерба и предупреждение граждан о возможных последствиях при совершении коррупционных преступлений.

2. Совершенствование процесса формирования эталонов службы у сотрудников правоохранительных органов, проходящих первоначальное обучение, связанных с высоким правовым уровнем развития компетенций, не совместимых с коррупционными проявлениями в обществе.

Значительный прирост преступлений коррупционной направленности за последние годы стал итогом неблагоприятных социально-культурных сдвигов, возникших после развала Советского Союза на постсоветском пространстве. Проведённые реформы способствовали появлению новых демократических прав и свобод человека и гражданина возрождаемого государства, развитию современных экономических процессов, свободе слова и вероисповедания. Однако они же стали движущей силой криминальных течений, совершенно нетипичных для криминалитета бывшего Советского Союза до 1991 года.

По мнению С.А. Воронцова и В.Л. Ляхова, «снижение уровня профессионализма сотрудников правоохранительных органов, обусловленное перманентным реформированием силовых ведомств, способствовало не только активизации преступности в её наиболее опасных проявлениях, но и привело к разрушению культуры народа, снижению значения нравственных начал, утрате духовности, девальвации ценности права. Фактически можно говорить о кризисе культуры, который, при непринятии должных мер, в конечном счёте, неминуемо приведёт к падению власти» [4, с. 56].

Толерантное отношение сотрудников силовых ведомств к коррупции в разрезе структуры самой правоохранительной системы является одной из угрожающей причин, способствующей совершению преступных посягательств коррупционного характера. Ощущение вседозволенности помогает избежать наказания и создаёт условия для формирования преступных сообществ как в конкретном органе правопорядка, так и на межведомственном уровне.

К групповой взятке по предварительной договорённости, либо осуществлённой организованным сообществом, применяется более серьёзная мера наказания, но расследовать преступления данного вида намного тяжелее. 
Внедрение в образовательные организации МВД России специальных курсов, обучающих антикоррупционному поведению и опирающихся на антикоррупционное законодательство, значительно увеличит уровень антикоррупционного просвещения [8, с. 35]. Весьма важно воспитывать у молодёжи антикоррупционные идеалы, особенно у будущих сотрудников правоохранительных органов.

3. Усиление мер по надзору и контролю.

Следует признать высокоэффективной деятельность комитетов, обязанностью которых является предупреждение конфликта интересов, аттестация государственных, муниципальных служащих и военнообязанных.

Активную работу в данном направлении ведёт Генеральная прокуратура Российской Федерации, надзирающая за исполнением законодательства Российской Федерации по противодействию коррупционным преступлениям, а также организующая экспертизу антикоррупционнонного законодательства в целом и нормативных правовых актов в частности. Активно аккумулируется передовой опыт мероприятий по контролю за доходами и расходами гражданского населения и должностных лиц, в обязанности которых включено предоставление данных сведений. Многократно прорабатываются тактика и методика раскрытия дел коррупционной направленности, участниками которых явились сотрудники органов внутренних дел и иных подразделений органов правопорядка [9, с. 109].

4. Проведение антикоррупционных профилактических мероприятий с личным составом правоохранительных органов.

О высокой эффективности данных мероприятий, подразумевающих многочисленные увольнения сотрудников правоохранительных органов, говорить не приходится, так как картина существенно не изменяется. В связи с проводимой в обязательном порядке переаттестацией, работой подразделений собственной безопасности данная мера является действенным средством сдерживания реальных и потенциальных лиц, причастных к коррупционным преступлениям, от совершения преступлений в данной сфере [10, с. 72].

5. Рационализация деятельности по осуществлению отбора кандидатов, впервые принимаемых на службу.

Кадровым подразделениям необходимо повысить требования к кандидатам на службу в правоохранительные органы, а именно, не брать на работу по протекции, обязательно принимать во внимание характеристику по месту прожива- ния, учёбы и работы. В приоритетном порядке принимать на службу в органы правопорядка лиц, прошедших срочную службу в Вооружённых Силах России. Учитывая постоянно изменяющуюся криминогенную ситуацию в стране и мире, необходимо менять методику отбора и обучения студентов юридических факультетов [11, c. 1372].

Данные меры в сфере противодействия коррупции являются сугубо индивидуальными, так как при отборе кандидатов на службу невозможно дать объективную оценку личным и деловым качествам кандидата.

6. Сотрудничество со средствами массовой информации.

Всестороннее осведомление широкой общественности об итогах работы органов внутренних дел по борьбе с преступлениями коррупционной направленности выступает действенной мерой профилактики при соблюдении определённых требований:

- любое лицо, совершившее преступное деяние, независимо от своего статуса, должно быть в обязательном порядке привлечено к строгой ответственности согласно законодательству Российской Федерации. Если наказания (соразмерного и оперативного) не последует, у лиц, совершивших такое преступление, может возникнуть ощущение вседозволенности. Следовательно, нужно принимать все меры для недопущения подобных случаев;

- «средства массовой информации должны отвечать за достоверность публикуемых сведений, так как являются инструментом соблюдения конституционных норм при информировании широкой общественности о проявлениях коррупции и результатах их расследования» [12, с. 71].

7. Необходимость взятия на вооружение практического опыта борьбы с преступлениями коррупционной направленности, подразделений правопорядка ряда иностранных государств.

Разрабатывая научную основу для формирования правовой практики борьбы с коррупционными преступлениями, важно принимать во внимание передовой мировой опыт таких стран, как Финляндия, Дания, Исландия, Сингапур, Швеция, Канада, Нидерланды, Люксембург, Норвегия, Швейцария, Великобритания, Гонконг, Австрия, Израиль, США, Чили, Германия, Япония [13, с. 91].

Подразделения правоохранительного направления указанных иностранных государств при организации мер противодействия коррупционным преступлениям опираются в основном на предупреждение преступлений и посяга- 
тельств криминогенного характера. Утверждение о возможности победы над коррупцией исключительно репрессивными мерами (китайский, северо-корейский варианты противодействия коррупции) представляется нам ошибочным, поскольку противоборство направлено в основном на лиц, совершивших данные преступления, а не на само явление - коррупцию.

8. Увеличение оплаты труда.

Важно подчеркнуть, что невысокая заработная плата не может быть обоснованием для коррупционного поведения. Определение детерминант возникновения коррупции помогает осознать, что коррупция возникает в результате нарушения принципа законности и стабильности демократических институтов, обеспечивающих контроль и ответственность органов государственного управления перед народом, который признается единственным источником власти в стране [14, с. 37].
Поводя итог, можно сделать вывод, что эффективным способом борьбы с коррупционными правонарушениями в правоохранительных органах выступают меры по их предупреждению. К данным мерам относятся: совершенствование законодательной базы, формирование реального механизма, стимулирующего трудовую деятельность, разработка новых методов отбора и расстановки кадров, реформирование системы профессионального обучения сотрудников (коррекция их негативных качеств и свойств).

Вышеперечисленные меры при правильном их использовании, а также соблюдение принципов непрерывности и повсеместности проведения могут значительно уменьшить количество коррупционных преступлений в органах внутренних дел и затруднить в дальнейшем появление данного вида преступных посягательств [15, с. 72].

\section{Список литературь}

1. Егоров В. А., Яковлев Н. А. Современный взгляд на коррупцию и методы борьбы с её проявлением // Успехи современной науки. - 2016. - № 12. - С. 119-123.

2. Александров А. И. Противодействие коррупции в современной России: уголовно-правовые и уголовно-процессуальные аспекты / Актуальные проблемы теории и практики противодействия коррупции в России и за рубежом : материалы Международной научно-практической конференции. - Омск: Омская юридическая академия, 2017. - С. 17-22.

3. Борков В. Н. Разграничение коррупционных проступков и коррупционных преступлений, совершаемых сотрудниками органов внутренних дел // Вестник Казанского юридического института МВД России. - 2016. - № 3 (25). - С. 82-86.

4. Воронщов С. А., Ляхов В. П. О дисциплинарной, административной и гражданско-правовой ответственности государственных и муниципальных служащих за коррупционные правонарушения // Наука и образование: хозяйство и экономика; предпринимательство; право и управление. 2017. - №. 4. - С. 54- 61.

5. Гуреев И. С. Анализ причин и факторов, порождающих коррупцию в правоохранительных органах // Ростовский научный журнал. - 2017. - № 3. - С. 6-19.

6. Кокурин А. В., Петров В. Е. Психолого-криминологическая характеристика личности сотрудников органов внутренних дел, осужденных за совершение преступлений коррупционной направленности // Вестник Университета имени О.Е. Кутафина. - 2017. - № 7 (35). - С. 111-123.

7. Петров В. Е. Прогнозирование степени антикоррупционной устойчивости поведения сотрудников Госавтоинспекции на основе Калифорнийского психологического опросника // Современные научные исследования и инновации. - 2016. - № 2 (58). - С. 247-252.

8. Собочкин В. М. Коррупция в правоохранительных органах: анализ причин и поиск способов противодействия // Ростовский научный журнал. - 2017. - № 2. - С. 27-43.

9. Стебенева Е. В. Преступления коррупционной направленности сотрудников органов внутренних дел / Уголовная политика, уголовное законодательство, правоприменительная практика : сборник научных статей / под ред. В. И. Тюнина. - Санкт-Петербург: Санкт-Петербургский государственный экономический университет, 2016. - С. 108-111.

10. Тирских A. А. Проблемы борьбы с коррупцией в органах внутренних дел // Известия Иркутской государственной экономической академии. - 2016. - № 4 (49). - С. 71-73.

11. Хачикян П. П. Общевоинские причины возникновения коррупции в Вооружённых силах Российской Федерации // Молодой ученый. - 2016. - № 11. - С. 1371-1374. 
12. Хечиев Б. Б. Состояние коррупции и меры противодействия коррупции в современном обществе // Молодой ученый. - 2017. - № 34. - С. 70-73.

13. Воронцов С. А. Об использовании в противодействии коррупции в России основных принципов зарубежных антикоррупционных технологий, показавших высокую эффективность // Юристъ-правоведъ. - 2011. - № 1. - С. 88-94.

14. Макаева К. И. Региональные аспекты коррупционных проявлений: состояние и перспективы // Новые технологии. - 2012. - № 1. - С. 35-41.

15. Ломов А. М. Проблемы противодействия коррупции в органах внутренних дел // Вестник Тюменского государственного университета. - 2014. - № 2. - С. 69-75.

\section{References}

1. Yegorov V. A., Yakovlev N. A. Sovremennyy vzglyad na korruptsiyu i metody bor'by s yeyo proyavleniyem // Uspekhi sovremennoy nauki. - 2016. - № 12. - S. 119-123.

2. Aleksandrov A. I. Protivodeystviye korruptsii v sovremennoy Rossii: ugolovno-pravovyye i ugolovno-protsessual'nyye aspekty / Aktual'nyye problemy teorii i praktiki protivodeystviya korruptsii $\mathrm{v}$ Rossii i za rubezhom : materialy Mezhdunarodnoy nauchno-prakticheskoy konferentsii. - Omsk: Omskaya yuridicheskaya akademiya, 2017. - S. 17-22.

3. Borkov V. N. Razgranicheniye korruptsionnykh prostupkov i korruptsionnykh prestupleniy, sovershayemykh sotrudnikami organov vnutrennikh del // Vestnik Kazanskogo yuridicheskogo instituta MVD Rossii. - 2016. - № 3 (25). - S. 82-86.

4. Vorontsov S. A., Lyakhov V. P. O distsiplinarnoy, administrativnoy i grazhdansko-pravovoy otvetstvennosti gosudarstvennykh i munitsipal'nykh sluzhashchikh za korruptsionnyye pravonarusheniya // Nauka i obrazovaniye: khozyaystvo i ekonomika; predprinimatel'stvo; pravo i upravleniye. - 2017. - № 4. - S. 54-61.

5. Gureyev I. S. Analiz prichin i faktorov, porozhdayushchikh korruptsiyu v pravookhranitel'nykh organakh // Rostovskiy nauchnyy zhurnal. - 2017. - № 3. - S. 6-19.

6. Kokurin A. V., Petrov V. Ye. Psikhologo-kriminologicheskaya kharakteristika lichnosti sotrudnikov organov vnutrennikh del, osuzhdennykh za soversheniye prestupleniy korruptsionnoy napravlennosti // Vestnik Universiteta imeni O.Ye. Kutafina. - 2017. - № 7 (35). - S. 111-123.

7. Petrov V. Ye. Prognozirovaniye stepeni antikorruptsionnoy ustoychivosti povedeniya sotrudnikov Gosavtoinspektsii na osnove Kaliforniyskogo psikhologicheskogo oprosnika // Sovremennyye nauchnyye issledovaniya i innovatsii. - 2016. - № 2 (58). - S. 247-252.

8. Sobochkin V. M. Korruptsiya v pravookhranitel'nykh organakh: analiz prichin i poisk sposobov protivodeystviya // Rostovskiy nauchnyy zhurnal. - 2017. - № 2. - S. 27-43.

9. Stebeneva Ye. V. Prestupleniya korruptsionnoy napravlennosti sotrudnikov organov vnutrennikh del / Ugolovnaya politika, ugolovnoye zakonodatel'stvo, pravoprimenitel'naya praktika : sbornik nauchnykh statey / pod red. V. I. Tyunina. - Sankt-Peterburg: Sankt-Peterburgskiy gosudarstvennyy ekonomicheskiy universitet, 2016. - S. 108-111.

10. Tirskikh A. A. Problemy bor'by s korruptsiyey v organakh vnutrennikh del // Izvestiya Irkutskoy gosudarstvennoy ekonomicheskoy akademii. - 2016. - № 4 (49). - S. 71-73.

11. Khachikyan P. P. Obshchevoinskiye prichiny vozniknoveniya korruptsii v Vooruzhonnykh silakh Rossiyskoy Federatsii // Molodoy uchenyy. - 2016. - № 11. - S. 1371-1374.

12. Khechiyev B. B. Sostoyaniye korruptsii i mery protivodeystviya korruptsii v sovremennom obshchestve // Molodoy uchenyy. - 2017. - № 34. - S. 70-73.

13. Vorontsov S. A. Ob ispol'zovanii v protivodeystvii korruptsii v Rossii osnovnykh printsipov zarubezhnykh antikorruptsionnykh tekhnologiy, pokazavshikh vysokuyu effektivnost' // Yurist»-pravoved». - 2011. - № 1. - S. 88-94.

14. Makayeva K. I. Regional'nyye aspekty korruptsionnykh proyavleniy: sostoyaniye i perspektivy // Novyye tekhnologii. - 2012. - № 1. - S. 35-41.

15. Lomov A. M. Problemy protivodeystviya korruptsii v organakh vnutrennikh del // Vestnik Tyumenskogo gosudarstvennogo universiteta. - 2014. - № 2. - S. 69-75.

() Грачев Ю.А., Никишкин А.В., Ветрова Е.В., 2019

Статья поступила в редакцию 8.06.2019 г. 